\title{
Serum cytokine levels in autoimmune and non-autoimmune hyperthyroid states
}

L.S. $W$ ard $^{1}$ and G.A. Fernandes ${ }^{2}$

\author{
${ }^{1}$ Laboratório de Genética Molecular do Câncer, Departamento de Clínica Médica and \\ ${ }^{2}$ Departamento de Patologia Clínica, Faculdade de Ciências M édicas, \\ Universidade Estadual de Campinas, Campinas, SP, Brasil
}

\section{Correspondence \\ L.S. Ward \\ GEM OCA, Clínica Médica \\ FCM, UNICAMP \\ 13081-970 Campinas, SP \\ Brasil \\ Fax: + 55-19-289-4107 \\ E-mail: ward@ unicamp.br \\ Publication supported by FAPESP.}

Received April 5, 1999

Accepted November 4, 1999

\section{Abstract}

Although the role of interleukin-2 (IL-2) and interferon gamma ( $\gamma$ IFN) is still poorly understood in hyperthyroid diseases, it is reasonable to assume that these cytokines may be present at higher levels in Graves' disease (GD) than in other primarily non-autoimmune thyroid diseases. In order to look for an easy method to distinguish GD from primarily non-autoimmune causes of hyperthyroidism, we compared 13 healthy individuals with 21 treated and untreated hyperthyroid GD patients and with 19 patients with hyperthyroidism due to other etiologies: 7 cases of multinodular goiter, 5 cases of excessive hormone replacement and 7 cases of amiodarone-associated hyperthyroidism. All patients presented low TSH levels and a dubious clinical thyroid state. We found a good correlation between TSH and serum IL-2 levels $(\mathrm{r}=0.56 ; \mathrm{P}<0.01)$. Serum IL-2 $(\mathrm{P}<0.01)$ and $\gamma \operatorname{IFN}(\mathrm{P}<0.01)$ levels were lower in the hyperthyroid group of patients than in control subjects, suggesting a depressed TH1 pattern in the T-cell subset of hyperthyroid patients. GD had normal IL-2 levels, while patients with other forms of thyrotoxicosis presented decreased IL-2 levels $(\mathrm{P}<0.05)$. There was no difference between treated and untreated GD patients. We suggest that the direct measurement of serum IL-2 level may help to confirm hyperthyroidism caused by GD.

Since cytokines have a pivotal role in the generation and perpetuation of immune and inflammatory responses, it has been suggested that these polypeptide mediators may also be involved in the development and perpetuation of autoimmune diseases (1). However, their role in human thyroid physiology and in hyperthyroid states is still poorly understood. In Graves' disease (GD) a plethora of different cytokines are produced by intrathyroid lymphocytes and also by follicular thyroid cells $(2,3)$. There are some indications that this cytokine production may be altered $(4,5)$. A disturbed immune regulation causing a dominance of $\mathrm{TH} 2$ cytokine production has been postulated to be crucial in the pathogenesis of the disease (6). Also, serum cytokine levels seem to show a good correlation with endocrine status, indicating that they could even function as markers of thyroid activation in GD (7). On the other hand, it is difficult to evaluate the influence of hyperthyroxinemia by itself, since antithyroid drugs interfere with cytokine production (8-10).

Our hospital receives many patients from 
iodine-deficient regions and many individuals taking amiodarone and other drugs that cause a relatively high frequency of borderline TSH levels (11). We do not perform routine measurements of thyroid-stimulating antibodies, and the clinical signs and symptoms of the patients are not always so clear, especially in amiodarone-associated hyperthyroid patients. Hence, it is not always easy to determine the cause of thyrotoxicosis. In order to look for an easy method to distinguish GD from other primarily nonautoimmune thyroid diseases, we compared GD with other conditions producing hyperthyroidism but considered not to have an autoimmune primary etiology, including multinodular goiter, excessive amounts of thyroid hormone, amiodarone-induced hyperthyroidism, and with normal healthy control subjects. Our aim was to determine whether cytokine concentration in blood serum can distinguish GD from other nonautoimmune states.

For this purpose, after approval by the Medical Ethics Committee, we studied 13 healthy volunteers ( 6 males and 7 females; median age, 24 years; range, 21-27 years) in an initial investigation designed to provide normal parameters for our cytokine assays. Forty hyperthyroid outpatients whose hyperthyroid picture has been clinically difficult to appraise were enrolled in our study. TSH and free T4 (fT4) measurements confirmed the diagnosis. Patients whose thyroid antibody levels were higher than $500 \mathrm{IU} / \mathrm{ml}$ were excluded from the study. After careful clinical examination, a blood sample was obtained from each subject for serum TSH, fT4, anti-thyroglobulin (TgAb) and anti-peroxidase (TPOAb) antibody, interleukin-2 (IL2 ) and interferon gamma ( $\gamma$ IFN) determinations. All patients presented TSH levels below the normal range. None of the patients or controls had infectious diseases or other autoimmune diseases. Twenty-one subjects had Graves' disease whereas in the other 19 patients, hyperthyroidism was primarily at- tributed to non-autoimmune diseases. The patients were divided into the following groups: group I - 21 patients (6 males and 15 females; median age, 34 years; range, 12 to 60 years) had a clinically well-established diagnosis of Basedow-Graves' disease. Eight of these subjects were newly diagnosed, untreated hyperthyroid patients. The other 13, although already on thionamide therapy, still presented depressed TSH levels. Group II - 7 patients ( 1 male, 6 females; median age, 51 years; range, 42 to 72 years) with a recent clinical diagnosis of multinodular goiter confirmed by ultrasonography and/or fine needle aspiration cytology. No one was receiving any treatment. Group III - 5 patients ( 2 males, 3 females; median age, 42 years; range, 18 to 62 years) with pituitary deficiency and using excessive amounts of levothyroxine. Four of these five patients had undergone surgery for pituitary tumors and the fifth had a diagnosis of Sheehan disease. Group IV - 7 patients ( 1 male, 6 females; median age, 48 years; range, 42 to 65 years) with amiodarone-associated hyperthyroidism. These patients had received a median dose of $400 \mathrm{mg} /$ day of the antiarrythmic drug for four years on average in order to control life-threatening cardiac arrhythmia. At the time of this investigation, all were considered to be clinically stable. No one showed any evidence of any previous or concomitant thyroid disease when submitted to clinical examination, ultrasonography and laboratory evaluation.

Blood samples were obtained between 9:00 and 13:00 $\mathrm{h}$ and the sera were kept frozen at $-25^{\circ} \mathrm{C}$ until the time for use. Cytokine determinations were run using single kits to increase test precision. TSH and fT4 were determined using fluometric enzyme immunoassays (Baxter Diagnostic Inc., Deerfield, IL, USA). The TSH assay had a minimal detectable dose of $0.05 \mathrm{U} / 1$, with normal values ranging from 0.38 to $6.15 \mathrm{U} / 1$. fT4 had a functional sensitivity of $0.2 \mathrm{ng} / \mathrm{dl}$, with normal values ranging from 0.74 to 2.1 ng/dl. Anti-thyroglobulin and anti-peroxi- 
dase antibodies were measured using immunoradiometric quantitative assays (Serono, Rome, Italy); intra- and inter-assay variation was 5 and $6 \%$, respectively, with a sensitivity of $1.0 \mathrm{IU} / \mathrm{ml}$ for TPOAb. We considered antibody values higher than $100 \mathrm{IU} / \mathrm{ml}$ to be positive.

IL-2 and $\gamma$ IFN were measured using solidphase enzyme immunoassay kits (Genzyme Diagnostics, Cambridge, MA, USA). Both IL-2 and $\gamma$ IFN kits had a detection limit of $100 \mathrm{pg} / \mathrm{ml}$ and the intra- and inter-assay coefficients of variation were 3.2 and $9.5 \%$, respectively, for IL-2 and 6.9 and $10.5 \%$, respectively, for $\gamma \mathrm{IFN}$.

Data are reported as means \pm SEM. Since the results did not show a normal distribution, they were analyzed by the KruskalWallis (H statistics), $\chi^{2}$ or Wilcoxon's rank sum ( $Z$ statistics), as appropriate. Correlations between different parameters were calculated by linear regression ( $\mathrm{r}$ statistics). The level of significance was set at $\mathrm{P}<0.05$. For statistical purposes, undetectable cytokine levels were assigned an arbitrary value corresponding to the lowest detectable amount for each assay.

The hyperthyroid groups (I-IV) and the control group were similar in terms of age and sex $\left(\mathrm{H}\right.$ and $\left.\chi^{2}=\mathrm{NS}\right)$. No control subject presented positive thyroid antibodies. The mean values measured in the control groups showed normal thyroid status ( $\mathrm{TSH}=1.94 \pm$ $0.07 \mathrm{U} / 1$ and $\mathrm{fT} 4=1.36 \pm 0.42 \mathrm{ng} / \mathrm{dl})$ and cytokine parameters (IL-2 $=1501.53 \pm 416.44$ $\mathrm{pg} / \mathrm{dl}$ and $\gamma \mathrm{IFN}=135.30 \pm 37.52 \mathrm{pg} / \mathrm{dl})$. In the hyperthyroid groups, TSH levels were $0.04 \pm 0.01,0.05 \pm 0.02,0.13 \pm 0.04,0.09 \pm$ $0.03 \mathrm{U} / 1$, and fT4 levels were $3.94 \pm 0.39$, $2.86 \pm 0.85,1.96 \pm 0.26,1.70 \pm 0.25 \mathrm{ng} / \mathrm{dl}$ for groups I to IV. IL-2 and $\gamma$ IFN levels were $1671.57 \pm 364.77$ and $112.35 \pm 24.51 \mathrm{pg} / \mathrm{dl}$ for group I, $874.28 \pm 330.44$ and $129.01 \pm$ $48.76 \mathrm{pg} / \mathrm{dl}$ for group II, $928.00 \pm 415.01$ and $90.66 \pm 40.54 \mathrm{pg} / \mathrm{dl}$ for group III, and $416.00 \pm 157.23$ and $102.16 \pm 38.62 \mathrm{pg} / \mathrm{dl}$ for group IV, respectively.
There was a strong correlation between serum TSH and IL-2 levels in all measurements $(\mathrm{r}=0.56 ; \mathrm{P}<0.01)$. Serum TSH $(\mathrm{H}=$ 5.29; $\mathrm{P}=0.15)$, IL-2 $(\mathrm{H}=4.94 ; \mathrm{P}=0.17)$ and $\gamma \mathrm{IFN}(\mathrm{H}=2.84 ; \mathrm{P}=0.41)$ levels were similar in all four hyperthyroid groups, but serum IL-2 $(Z=5.27 ; \mathrm{P}<0.001)$ and $\gamma \mathrm{IFN}(\mathrm{Z}=5.25$; $\mathrm{P}<0.001)$ levels were higher in hyperthyroid patients than in the control group.

There was no significant difference in serum IL-2 levels between GD patients and control subjects $(Z=0.18 ; P=0.42)$ but GD patients had significantly lower $\gamma \mathrm{IFN}$ levels $(Z=2.16 ; P=0.01)$. Serum IL-2 and $\gamma I F N$ levels were similar in treated and untreated GD patients $(\mathrm{Z}=0.75 ; \mathrm{P}=0.22$ for IL-2 and $Z=1.36 ; P=0.08$ for $\gamma I F N)$.

Comparison of GD patients (group I) with groups II, III and IV (non-autoimmune hyperthyroid patients) showed that group I presented higher serum IL-2 levels $(Z=1.74$; $\mathrm{P}=0.04)$ but similar serum $\gamma \mathrm{IFN}$ levels $(\mathrm{Z}=$ $0.34 ; \mathrm{P}=0.36)$. Non-autoimmune hyperthyroid patients also showed lower serum IL-2 and $\gamma \mathrm{IFN}$ levels than the control subjects $(\mathrm{Z}$ $=4.62 ; \mathrm{P}<0.001$ and $\mathrm{Z}=4.49 ; \mathrm{P}<0.001$, respectively). The 3 non-autoimmune hyperthyroid patient subgroups had similar serum IL-2 and $\gamma$ IFN levels $(\mathrm{H}=2.89 ; \mathrm{P}=0.23$ and $\mathrm{H}=0.46 ; \mathrm{P}=0.79$, respectively).

The pattern of cytokine expression within a diseased tissue and serum cytokine profile can provide important information about pathogenesis. In GD, where thyroid hyperfunction induced by stimulating antibodies predominates over tissue destruction, a TH2 dominance would be expected. Also, it would be reasonable to predict higher cytokine levels in Graves' disease than in nodular goiters or other primarily non-autoimmune diseases. However, literature data are difficult to interpret. Besides methodological caveats, there are many factors interfering with immune regulation of humans, like counterregulatory cytokines and the effect of drugs. As also observed in some other autoimmune diseases, some serum cytokines may serve 
as disease activity markers in GD $(7,8)$. In particular, a form of the $\alpha$ chain of IL-2, called soluble IL-2 receptor, seems to increase in response to T3 stimulation, correlating positively with serum thyroid hormone concentrations $(7,8,12)$.

In the present study, we evaluated the serum concentration of IL-2 and $\gamma$ IFN levels in hyperthyroid patients, comparing $21 \mathrm{GD}$, untreated and on thionamide therapy, with 19 patients with non-autoimmune hyperthyroid diseases. We found lower levels of serum IL-2 and $\gamma \mathrm{IFN}$ in the hyperthyroid patients than in the control subjects $(\mathrm{P}<0.01)$, suggesting that hyperthyroidism induces a depressed TH1 pattern. This is possibly one more evidence of the direct effect of thyroid hormone levels over human lymphocytes in vivo independent of the etiology of the hyperthyroidism $(8,13)$. There was a significant elevation in hyperthyroid patient mean IL-2 serum levels compared to normal individuals $(\mathrm{P}<0.001)$. This cytokine could come from the thyroid gland. Watson et al. (2), using the reverse transcription-polymerase chain reaction (RT-PCR), demonstrated that a wide variety of cytokines are produced by infiltrating mononuclear cells and by folli- cular cells in GD, in contrast to the poor cytokine production observed in multinodular goitrous patients. Thionamide treatment of GD patients could have been a bias in our data, interfering with the expression of cytokines, but we found no difference between treated and non-treated patients (14).

In conclusion, we found major differences in serum IL-2 levels between GD and other hyperthyroid states. More data, such as the quantification of serum IL-4 and IL-10 levels in both GD and non-autoimmune hyperthyroid patients are necessary in order to clarify the role of cytokines. However, this easily measurable cytokine could be of help in the not infrequent situation in which clinical evaluation and laboratory data are insufficient to distinguish GD from other hyperthyroid states.

\section{Acknowledgments}

The authors would like to thank Roberto C. Stahl, Paulo C. Granado, Laurione C. Oliveira and David A. Silva for skillful technical help. We are also very grateful to Prof. Rui M.B. Maciel (UNIFESP) for valuable comments and suggestions.

\section{References}

1. Volpé R (1993). The role of cytokines in the development of autoimmune thyroid disease. Thyroid, 3: 177-178.

2. Watson PF, Pickerill AP, Davies R \& Weetman AP (1994). Analysis of cytokine gene expression in Graves' disease and multinodular goiter. J ournal of Clinical Endocrinology and Metabolism, 79: 355-360.

3. Weetman AP, Aijan RA \& Watson PF (1997). Cytokines and Graves' disease. Bailliere's Clinical Endocrinology and Metabolism, 11: 481-497.

4. Eisenstein $Z$, Engelsman $E$, Wiss $M$, Kalechman Y \& Sredni B (1994). Modulation of the IL-2 production defect in vivo in Graves' disease. Clinical and Experimental Immunology, 96: 323-328.

5. Hirooka $Y$, Mitsuma T, Nogimori $T \&$ Ishizuki $Y$ (1993). Deregulated production of interleukin-8 (IL-8) in autoimmune thy- roid disease studied by newly developed IL-8 radioimmunoassay. Endocrine Regulation, 27: 11-15.

6. Kallmann $B A$, Huther $M$, Tubes $M$, Feldkamp J, Bertrams J, Gries FA, Lampeter EF \& Kolb H (1997). Systemic bias of cytokine production toward cellmediated immune regulation in IDDM and toward humoral immunity in Graves' disease. Diabetes, 46: 237-243.

7. Komorowski J, J ankiewicz J, Robak $\mathrm{T}$, Blasinska-Morawiec $\mathrm{M}$ \& Stepien $H$ (1998). Cytokines serum levels as the markers of thyroid activation in Graves' disease. Immunology Letters, 60: 143-148.

8. Koukkou E, Panayioditis P, AlevizouTerzaki V \& Thalassinos N (1995). Serum soluble interleukin-2 receptors as an index of the biological activity of thyroid hormones in hyperthyroidism. J ournal of Endocrinological Investigation, 18: 253257.

9. Tsatoulis A, Vlachoyiannopoulos PG, Dalekos GN, J ohnson EO \& Moutsopoulos HM (1995). Increased serum interleukin-1 beta during treatment of hyperthyroidism with antithyroid drugs. European J ournal of Clinical Investigation, 25: 654658.

10. Paggi A, Amoroso A, Ferri GM, Mariotti A, Pellegrino C \& Afeltra A (1986). Effect of the anti-thyroid drug methimazole on interleukin-1 and interleukin-2 levels in vitro. Clinical Endocrinology, 25: 133-142.

11. Ward LS, Santos AO \& Fernandes GA (1998). Prevalence and follow-up of borderline thyrotropin (TSH) levels in a general hospital. Brazilian J ournal of Clinical Therapeutics, 24: 147-151. 
12. Nakanishi K, Taniguchi $Y \&$ Ohta $Y$ (1991). Increased soluble interleukin 2 receptor levels in autoimmune thyroid disease. Acta Endocrinologica, 125: 253-258.

13. Mariotti $S$, Caturegli $P$, Barbesino G, Marinó M, Del Petre GF, Chiovato L, Tonacchera M, De Carli M \& Pinchera A
(1992). Thyroid function and thyroid autoimmunity independently modulate serum concentration of soluble interleukin 2 (IL-2) receptor (IL-2T) in thyroid diseases. Clinical Endocrinology, 37: 415-422.

14. Paggi A, Amoroso A, Ferri GM, Mariotti A, Pellegrino C \& Afeltra A (1998). Methima- zole treatment in Graves' disease: behavior of CD5+B lymphocytes and regulatory T cell subsets. European Review of Medical and Pharmacological Sciences, 2: 1119. 